\title{
EDITORIAL REVIEW
}

\section{Personality diatheses: a superior explanation than disorder}

\author{
PETER TYRER* \\ Department of Psychological Medicine, Imperial College London, London, UK
}

\begin{abstract}
Diatheses confer vulnerability to disorder but are not necessarily manifest overtly or consistently. It is suggested that the main empirical findings of studies with abnormal personality support the notion that they are diatheses rather than disorders. This includes their onset early in life, their variability of expression dependent on setting, their greater association with more severe disorders and their acceptance as intrinsic components of functioning by most suffering from these conditions. It is argued that a separate axis of classification for personality diatheses rather than disorders is justified.
\end{abstract}

\section{Introduction}

Personality disorders have represented a thorn in the side of psychiatric classification in psychiatry ever since they were first identified by Pinel ('manie sans dèlire') and Prichard nearly 200 years ago. They have generally been classified together with other psychiatric disorders but this has always been an uneasy association; on many occasions attempts at separation have been mounted on the grounds that these conditions are not the same as other disorders and do not really belong to psychiatry. Because of this concern the classification of personality disorder has been always been somewhat at arm's length from other mental disorders. This has shown itself most prominently in the adoption of Axis II for personality disorders in the third revision of the Diagnostic and Statistical Manual of Mental Disorders (APA, 1980). However, the arguments given for the separation were never very strong. In the Introduction to DSM-III the introduction of Axis II was justified as this ensures 'that consideration is given to the possible presence of disorders that are frequently overlooked when

* Address for correspondence: Professor Peter Tyrer, Department of Psychological Medicine, Imperial College, St Dunstan's Road, London W6 8RP, UK.

(Email: p.tyrer@imperial.ac.uk)

Presented at the XIIIth WPA World Congress, Cairo, Egypt, 10-15 September 2005. attention is directed to the usually more florid Axis I disorder' (APA, 1980, p. 23).

The classification of personality disorders (variously between 9 and 11 categories) since the introduction of DSM-III has also come in for severe criticism. It is now almost universally recognized that the lack of homogeneity between individual personality disorder categories, the great degree of overlap (mistakenly described as co-morbidity) between them, and the arbitrary nature of the division between normal personality and personality disorder, bears little relationship to personality abnormality in clinical or research practice (Livesley, 1987; Rutter, 1987; Blashfield \& Breen, 1989; Bronisch, 1992; Clark et al. 1997; Tyrer, 1999), so that as a consequence the diagnosis "personality disordernot otherwise specified' is generally the most commonly used in clinical practice and also frequently in research studies when close attention is being paid to the identification of individual disorders (Zanarini et al. 1998; Karterud et al. 2003). As a consequence, there are now suggestions that Axis I and II should be joined again (Krueger, 2005), or if personality disorder remains in the classification it should be in the form of a dimensional system based on traits (Widiger $\&$ Simonsen, 2005). Although this is a solution, and there is abundant evidence that the dimensional model is superior to the categorical one in 
the description of personality disorders (Clark et al. 1997), there is an alternative that might be better able to explain the existing empirical data on personality disorder.

\section{Why personality diathesis?}

One of the constant features in the definition of personality disorder over the years is the notion, almost a fixed criterion of disorder, that the condition develops in childhood or early adolescence with its manifestations being shown by the time of early adult life and continuing, at least into middle age. The evidence that these conditions provoke personal suffering and distress to others is derived from Schneider's famous aphorism that people with 'personality disorders suffer from their disorder and cause society to suffer' (Schneider, 1923), and has influenced ICD and DSM classifications for over 40 years. However, the alternative notion that these conditions constitute a diathesis, conferring a tendency to develop other psychiatric disorders or abnormal behaviours but at other times being quiescent, might be considered to fit the data somewhat better. The diathesis, or vulnerability, model identifies an innate tendency to develop other disorders more frequently, and both to increase their intensity and frequency of recurrence. Thus, those with abnormal personalities can be seen as having an Achilles' heel that allows the individual to function normally in most circumstances but when faced with certain situations becomes activated and precipitates problems. The origin of the vulnerability may be both genetic or environmental with interactions between them at different times (Caspi et al. 2003) and, once developed, there is relative persistence of the vulnerability features, but not the expression of distress or disorder. Several recent developments in personality disorder research can be interpreted as giving support to this notion.

\section{Early onset}

One of the core notions of personality as a concept is that it develops fairly early in life although may not be fully manifest until early adulthood. Abnormal personality function developing later in life can follow a variety of precipitants, most notably brain injury, and is acknowledged as 'personality change' rather than disorder (WHO, 1992). The notion of longstanding vulnerability in the form of diathesis equates well with early onset.

\section{Lack of persistence}

One of the interesting aspects of recent personality disorder research is a change in attitudes towards the relatively reported poor temporal reliability of personality disorders (Zimmerman, 1994; Clark \& Harrison, 2001). Because poor reliability conflicted with the universal notion that personality disorders should be 'ingrained and persistent' the assumption was made that poor reliability must be a fault of the instruments used to rate disorder rather than instability of the disorder (Loranger et al. 1991). This has now changed, mainly as a result of a large US study, the Collaborative Longitudinal Personality Disorder study (CLPS). This study, still in progress, records the progress of four named personality disorders in patients presenting in clinical settings. The results have shown that all four disorders, borderline, avoidant, obsessive-compulsive and schizotypal personality disorders, improve steadily over 5 years and fewer than half satisfy the criteria for personality disorder consistently over a 1- to 2-year period (Shea et al. 2002). Other recent studies also demonstrate this lack of stability of DSM personality disorders (Grilo et al. 2001; Seivewright et al. 2002).

Such instability is consistent with the diathesis model, which predicts that the expression of disorder is often hidden, with exacerbations occurring in response to events, and that so a population seen in the clinic at a time of distress will tend to improve during the process of regression towards the mean. The diathesis model recognizes a natural ebb and flow in the expression of abnormal clinical features and is quite comfortable with the notion that at one time the vulnerability may provoke a dramatic deterioration in function whereas at others it appears to be almost in abeyance. It would also predict that when environmental adjustment is optimal the personality problems would be exhibited to a much lesser extent (Tyrer et al. 2003a).

The notion of personality vulnerability has been recognized on several occasions previously, but it has been confined to minor degrees of personality disturbance, such as the 'personality accentuation' of Karl Leonhard (1968) and the 
'stress-induced personality disorder' of Reich (2002). The diathesis model is not confined to minor disturbance but covers the whole range.

\section{Continued poor social function}

Despite improvements in the behavioural items required for personality disorder diagnosis, longitudinal studies show that social dysfunction persists (Seivewright et al. 2004; Skodol et al. 2005). This could also be in keeping with the diathesis hypothesis of persistent maladaptation as the core of the condition. Despite a range of potential attempts to improve current personality status, which is best described as personality function (Bronisch \& Klerman, 1991), the key vulnerability persists.

\section{Extensive co-occurrence with other disorders}

A general diathesis model allows for all personality abnormality to share in provoking vulnerability. However, personality shows considerable variation and four major higher order traits have been identified in most studies over the last 40 years. These have received varying titles but include the traits of social withdrawal and isolation (schizoid dimension), impulsiveness and extraversion (dramatic dimension), anxiousness and dependence (neurotic dimension) and conscientiousness and doubt (the obsessive-compulsive dimension), conveniently summarized by Mulder \& Joyce (1997) as the four a's, antisocial, asocial, asthenic and anankastic. They are also linked to the internalizing tendencies (to mood and anxiety disorders) and externalizing ones (to substance use and antisocial activities). To varying degrees each of these major traits confer a level of specific vulnerability to a group of mental state disorders, for example, it is more likely for those with greater impulsiveness and dramatic behaviour to develop substance misuse disorder and for those with greater anxiousness to develop phobic and other anxiety disorders (Tyrer et al. 1992, 2004; Khan et al. 2005; Krueger, 2005; Moran et al. 2006).

\section{Egosyntonicity}

Most personality abnormalities, despite creating problems for the individual, are nonetheless regarded as intrinsic to normal function and too much part of this to be changed. This is an important distinction of most personality disorders that leads to most of them being treatment-rejecting (type R) as opposed to treatment-seeking (type S) (Tyrer et al. 2003 b). In other words, they are egosyntonic, not egodystonic (Alexander, 1930). As a consequence, most people with personality disorder do not present for treatment directly, but with another disorder that may or may not be related to the personality disturbance. As such, the personality problems are latent (and were encouraged to be exposed by the adoption of Axis II for personality disorders in DSM-III), but are still highly relevant to achieve a full clinical picture. It can be argued that most diatheses are likely to be egosyntonic as they are always present to some degree and in general terms could be described as constitutional.

\section{Spectrum hypothesis of personality and mental state disorders}

It has been suggested that personality disorders constitute part of the spectrum of psychiatric disorders and intervene between the full expression of the disorder and its absence (Siever \& Davis, 1991). Although this has been heuristically valuable in stimulating research the only good example of a personality disorder fitting within this spectrum is schizotypal personality disorder, a condition which has some of the features of schizophrenia and which is found in the relatives of those with the condition, but does not have all the full symptomatology of the condition. This was first shown in the Danish adoption studies many years ago and has continued to be reinforced by subsequent work, including the evidence that low-dose antipsychotic drug treatment might be effective (Goldberg et al. 1986; Koenigsberg et al. 2003).

Where the diathesis model is superior to the spectrum one is in explaining the much greater association of multiple Axis I pathology in the presence of personality disorder (Tyrer et al. 1997). The diathesis model predicts greater Axis I co-morbidity for those conditions whose threshold of expression is lower because of greater vulnerability, and this vulnerability persists side by side with the mental state disorder. The spectrum model would predict that the mental state disorder would replace the personality one as the condition became more severe. Empirical studies have shown this is not the case. Thus, epidemiological studies have shown 
repeatedly that whilst the prevalence of personality disorder is only $4-5 \%$ in the community (Coid et al. 2006), this increases to $25-30 \%$ in primary care (Casey \& Tyrer, 1990; Moran et al. 2000) whereas high percentages are found in outpatients (Tyrer et al. 1983), with even higher proportions in community and specialist teams with more severe illness (Keown et al. 2002; Ranger et al. 2004). In general there is also greater intensity of symptoms in those who have co-occurrent personality disorders (Tyrer et al. 1990) and this also is difficult to explain with the spectrum concept but predicted readily by the diathesis one, which postulates greater tendency to recurrence as well as higher intensity of symptom expression.

\section{Categorical and dimensional classification}

The notion of vulnerability lends itself more readily to dimensional than categorical description. Again the empirical evidence in personality disorder suggests the dimensional approach is the best way of interpreting data (Clark et al. 1997; Grilo et al. 2001; Widiger \& Simonsen, 2005). Although there is increasing evidence that almost all mental disorders can be viewed dimensionally as there are no clear 'points of rarity' between 'disorder' and 'no disorder' (Kendell \& Jablensky, 2003) - but it is often important to have categories for clinical decision making. This is generally less important with personality disturbance, as it is only at the extreme end of disturbance that personality abnormality becomes so severe that important clinical decisions (e.g. detention in hospital) might be considered appropriate. The abandonment of the categorical model also helps to reduce the stigma associated with the description of personality abnormality and, when replaced by 'personality diathesis', together with a dimensional continuum, the term is more acceptable to patients as well as reflecting more accurately the practice of clinicians (Tyrer \& Johnson, 1996).

If personality can be viewed as a diathesis the justification for a separate axis of classification becomes stronger. It then allows assessments to be made of different domains of function and symptomatology. It may also allow some of the conditions currently classified under personality disorder to be moved to Axis I as they lack the essential components of the diathesis. This could include borderline personality disorder, which differs from others in being usually egodystonic, more help-seeking, a strong link to affective disorder (Coid, 1993; Tyrer, 1999; Zanarini et al. 2003) and a greater tendency to achieve complete remission, or to be more accurate, recovery (Zanarini et al. 2003). The attachment of the word 'diathesis' to those other personalities that bear relatively little resemblance to other conditions more appropriately called disorders, could offer significant advantages to a group of conditions that has been handicapped for decades by a classification system that has repeatedly failed to understand the fundamental nature of personality and its range of positive and negative expression.

\section{Declaration of Interest}

The author is the co-chair of the Section of Personality Disorders of the World Psychiatric Association and has received research grants from the Home Office, Wellcome Trust and National Forensic Programme of Mental Health for study of abnormal personality.

\section{References}

APA (1980). Diagnostic and Statistical Manual of Mental Disorders (3rd edn). American Psychiatric Association: Washington, DC.

Alexander, F. (1930). The neurotic character. International Journal of Psychoanalysis 11, 291-311.

Blashfield, R. \& Breen, M. (1989). Face validity of the DSM-III-R personality disorders. American Journal of Psychiatry 146, 15751579.

Bronisch, T. (1992). Diagnostik von Persönlichkeitstörungen nach den Kriterien aktueller internationaler Klassifikationssysteme. Verhaltenstherapie 2, 140-150.

Bronisch, T. \& Klerman, G. L. (1991). Personality functioning change and stability in relationship to symptoms and psychopathology. Journal of Personality Disorders 5, 307-317.

Casey, P. \& Tyrer, P. (1990). Personality disorder and psychiatric illness in general practice. British Journal of Psychiatry 156, 261-265.

Caspi, A., Sugden, K., Moffitt, T. E., Taylor, A., Craig, I. W., Harrington, H., McClay, J., Mill, J., Martin, J., Braithwaite, A. \& Poulton, R. (2003). Influence of life stress on depression: moderation by a polymorphism in the 5-HTT gene. Science 301, 386-389.

Clark, L. A. \& Harrison, J. A. (2001). Assessment instruments. In: Handbook of Personality Disorders: Theory, Research and Treatment (ed. W. John Livesley), pp. 277-306. Guilford: New York.

Clark, L. A., Livesley, W. J. \& Morey, L. (1997). Personality disorder assessment: the challenge of construct validity. Journal of Personality Disorders 11, 205-231

Coid, J. W. (1993). An affective syndrome in psychopaths with borderline personality disorder? British Journal of Psychiatry $\mathbf{1 6 2}$, 641-650.

Coid, J., Yang, M., Tyrer, P., Roberts, A. \& Singleton, N. (2006). Prevalence and correlates of personality disorder among adults aged 16-74 in Great Britain. British Journal of Psychiatry 188, 423-431.

Goldberg, S. C., Shulz, S. C., Shulz, P. M., Resnick, R. J., Haymer, R. M. \& Friedel, R. O. (1986). Borderline and schizotypal 
personality disorders treated with low dose thiothixene versus placebo. Archives of General Psychiatry 43, 680-686.

Grilo, C. M., Becker, D. F., Edell, W. S. \& McGlashan, T. H. (2001). Stability and change of DSM-III-R personality disorder dimensions in adolescents followed up 2 years after psychiatric hospitalisation. Comprehensive Psychiatry 42, 364-368.

Karterud, S., Pedersen, G., Bjordal, E., Braband, J., Friis, S. Haaseth, O., Haavaldsen, G., Irion, T., Leirvag, H., Torum, E. \& Urnes, O. (2003). Day treatment of patients with personality disorders: experiences from a Norwegian treatment research network. Journal of Personality Disorders 17, 243-262.

Kendell, R. \& Jablensky, A. (2003). Distinguishing between the validity and utility of psychiatric diagnoses. American Journal of Psychiatry 160, 4-12.

Kendler, K. S. \& Eaves, L. J. (1986). Models for the joint effects of genotype and environment on liability to psychiatric illness. American Journal of Psychiatry 143, 279-289.

Keown, P., Holloway, F. \& Kuipers, E. (2002). The prevalence of personality disorders, psychotic disorders and affective disorders amongst the patients seen by a community mental health team in London. Social Psychiatry and Psychiatric Epidemiology 37, 225229

Khan, A. A., Jacobson, K. C., Gardner, C. O. \& Kendler, K. S. (2005). Personality and comorbidity of common psychiatric disorders. British Journal of Psychiatry, 186, 190-196.

Koenigsberg, H. W., Reynolds, D., Goodman, M., New, A.S., Mitropoulou, V., Trestman, R. L., Silverman, J. \& Siever, L. J. (2003). Risperidone in the treatment of schizotypal personality disorder. Journal of Clinical Psychiatry 64, 628-634.

Krueger, R. F. (2005). Continuity of Axes I and II: towards a unified model of personality, personality disorders, and clinical disorders. Journal of Personality Disorders 19, 233-261.

Leonhard, K. (1968). Akzentuierte Persönlichkeiten. Verlag Volk und Gesundheit: Berlin.

Livesley, W. J. (1987). A systematic approach to the delineation of personality disorders. American Journal of Psychiatry 144, 772777.

Loranger, A. W., Lenzegweger, M. F., Gartner, A. F., Susman, V. L., Herzig, J., Zammit, G. K., Gartner, J. D., Abrams, R. C. \& Young, R. C. (1991). Trait-state artifacts and the diagnosis of personality disorders. Archives of General Psychiatry $\mathbf{4 8}$ $720-728$.

Moran, P., Coffey, C., Mann, A., Carlin, J. B. \& Patton, G. C. (2006). Personality and substance use disorders in young adults. British Journal of Psychiatry 188, 374-379.

Moran, P., Jenkins, R., Tylee, A., Blizard, R. \& Mann, A. (2000). The prevalence of personality disorder among UK primary care attenders. Acta Psychiatrica Scandinavica 102, 52-57.

Mulder, R. T. \& Joyce, P. R. (1997). Temperament and the structure of personality disorder symptoms. Psychological Medicine 27, 99-106.

Ranger, M., Methuen, C., Rutter, D, Rao, B. \& Tyrer, P. (2004). Prevalence of personality disorder in the caseload of an inner city assertive outreach team. Psychiatric Bulletin 28, 441443.

Reich, J. (2002). Clinical correlates of stress induced personality disorder. Psychiatric Annals 32, 581-588.

Rutter, M. (1987). Temperament, personality and personality disorder. British Journal of Psychiatry 150, 443-458.

Schneider, K. (1923). Die psychopathischen Persönlichkeiten. Springer: Berlin.

Seivewright, H., Tyrer, P. \& Johnson, T. (2002). Change in personality status in neurotic disorders. Lancet 359, 2253-2254.
Seivewright, H., Tyrer, P. \& Johnson, T. (2004). Persistent social dysfunction in anxious and depressed patients with personality disorder. Acta Psychiatrica Scandinavica 109, 104-109.

Shea, M. T., Stout, R., Gunderson, J., Morey, L. C., Grilo, C. M., McGlashan, T., Skodol, A. E., Dyck, I., Zanarini, M. C. \& Keller, M. B. (2002). Short-term diagnostic stability of schizotypal, borderline, avoidant, and obsessive-compulsive personality disorders. American Journal of Psychiatry 159, 2036-2041.

Siever, L. J. \& Davis, K. L. (1991). A psychobiologic perspective on the personality disorders. American Journal of Psychiatry 148 $1647-1658$.

Skodol, A. E., Pagano, M. E., Bender, D. S., Shea, M. T., Gunderson, J. G., Yen, S., Stout, R. L., Morey, L. C., Sanislow, C. A., Grilo, C. M., Zanarini, M. C. \& McGlashan, T. H. (2005). Stability of functional impairment in patients with schizotypal, borderline, avoidant, or obsessive-compulsive personality disorder over two years. Psychological Medicine 35, 443-451.

Tyrer, P. (1999). Borderline personality disorder: a motley diagnosis in need of reform. Lancet 354, 2095-2096.

Tyrer, P., Casey, P. \& Gall, J. (1983). The relationship between neurosis and personality disorder. British Journal of Psychiatry 142, 404-408.

Tyrer, P., Gunderson, J., Lyons, M. \& Tohen, M. (1997). Extent of comorbidity between mental state and personality disorders. Journal of Personality Disorders 11, 242-259.

Tyrer, P. \& Johnson, T. (1996). Establishing the severity of personality disorder. American Journal of Psychiatry 153, 1593-1597.

Tyrer, P., Mitchard, S., Methuen, C. \& Ranger, M. (2003b). Treatment-rejecting and treatment-seeking personality disorders: Type R and Type S. Journal of Personality Disorders 17, 265-270.

Tyrer, P., Seivewright, N., Ferguson, B., Murphy, S., Darling, C., Brothwell, J., Kingdon, D. \& Johnson, A. L. (1990). The Nottingham Study of Neurotic Disorder: relationship between personality status and symptoms. Psychological Medicine 20 423-431.

Tyrer, P., Seivewright, N., Ferguson, B. \& Tyrer, J. (1992). The general neurotic syndrome: a coaxial diagnosis of anxiety, depression and personality disorder. Acta Psychiatrica Scandinavica 85, 201-206.

Tyrer, P., Seivewright, H. \& Johnson, T. (2004). The Nottingham Study of Neurotic Disorder: predictors of 12 year outcome of dysthymic, panic and generalised anxiety disorder. Psychological Medicine 34, 1385-1394.

Tyrer, P., Sensky, T. \& Mitchard, S. (2003a). The principles of nidotherapy in the treatment of persistent mental and personality disorders. Psychotherapy and Psychosomatics 72, 350-356.

WHO (1992). ICD-10: Classification of Mental and Behavioural Disorders. World Health Organisation: Geneva.

Widiger, T. A. \& Simonsen, E. (2005). Alternative dimensional models of personality disorder. Journal of Personality Disorders 19, $110-130$.

Zanarini, M. C., Frankenburg, F., Dubo, E. D., Sickel, A. E., Trikha, A., Levin, A. \& Reynolds, V. (1998). Axis I comorbidity of borderline personality disorder. American Journal of Psychiatry 155, 1733-1739.

Zanarini, M. C., Frankenburg, F. R., Hennen, J. \& Silk, K. R. (2003). The longitudinal course of borderline psychopathology: 6-year prospective follow-up of the phenomenology of borderline personality disorder. American Journal of Psychiatry 160, 274-283.

Zimmerman, M. (1994). Diagnosing personality disorders. A review of issues and research methods. Archives of General Psychiatry 51 , 225-245. 